\section{How many letters in Bidwell's ghost? An investigation of the upper limits of full report from a brief visual stimulus}

\author{
DANIEL H. KRIEGMAN \\ and IRVING BIEDERMAN \\ State University of New York at Buffalo \\ Buffalo, New York 14226
}

and the use of a camera flash as a light source. If, during the flash, one looks at another person, a clear but apparition-like image results for which Bidwell's label seems most appropriate. The present investigation was intended less as a theoretical analysis than as a demonstration of the clarity of the ghost: whether it is sufficiently detailed to enable one to read as many letters from it as has been estimated from partial-report techniques.

\title{
METHOD
}

If observers are asked to report all the letters that they can see in a briefly presented array of letters, what is the maximum number of letters that can be accurately reported? Under such full report conditions, Sperling (1960) found that subjects were able to accurately report only 3 or 4 letters from a display of 12 letters. Sperling showed that this limit on full report was a consequence of a rapidly fading visual image and limitations on immediate memory. With a poststimulus cuing and sampling technique (along with the one devised by Averbach and Coriell, 1961), subjects were shown to have sufficient information to identify 12 of 16 letters in a brief display.

If the visual image was allowed to persist, could the number of letters in a full report equal the number of letters estimated to be available through the partial report technique? In the typical experiment exploring iconic storage, subjects are not dark adapted, nor is the luminance of the display particularly high. The present experiment sought to increase visual persistence by dark adapting the subjects and using displays of very high luminance. Under these conditions, it is possible to obtain clear positive afterimages of 3 to $4 \mathrm{sec}$ duration. Although the existence of such afterimages is not generally familiar to contemporary investigators (by informal poll), the existence of these aftereffects was known to students of vision in the last century. ${ }^{1}$ Bidwell (1894), Von Kries (1896), and Hamaker (1899) (all cited in Duke-Elder, 1932) refer to these afterimages as Bidwell's ghost, the pursuant image, and the satellite, respectively.

The clear, long-lasting positive afterimages can be readily obtained after $15 \mathrm{~min}$ of dark adaptation

This research was supported by research grants from the U.S. Army Research Institute for the Behavioral and Social Sciences (Grant MDA903-A-G-0003) and National Institutes of Mental Health (Grant MH33283) to Irving Biederman. The second author also held an NIH postdoctoral fellowship, MH07891. Requests for reprints should be sent to Daniel H. Kriegman, Solomon Carter Fuller Mental Health Center, 85 East Newton Street, Boston, Massachusetts 02118 , or Irving Biederman, Department of Psychology, State University of New York at Buffalo, 4230 Ridge Lea Road, Buffalo, New York 14226.

\begin{abstract}
Apparatus
A variable-intensity light source was made by placing a photographic strobe (Model Micro-Mini Two-Way; guide number: 28-30 Kodachrome II, color temperature: $5000^{\circ} \mathrm{K}$ ) inside a wooden box. One wall of the box was formed from two glass plates in which Kodak Wratten neutral density filters were placed. Five different filters were used with transmittance percentages of $80,10,1$, .1 , and .01 . The duration of the strobe was $1 \mathrm{msec}$.

The glass plates faced the target displays, which were 14 consonants and digits typed on the blank side of white index cards. Eleven of the 36 possible items were not used: $A, B, E, G$, $\mathrm{I}, \mathrm{M}, \mathrm{O}, \mathrm{Q}, \mathrm{U}, \mathrm{Y}$, and zero. The vowels and the letter $\mathrm{Y}$ were eliminated to reduce the pronounceability of the sequences. $G$, $Q$, and zero were eliminated because of their very high confusability, and $B$ was eliminated because it was confused with $P$ when taped. The displays were typed with an IBM Selectric typewriter with capital-letter Gothic typeface. There were three rows of characters. The top and bottom rows had five characters and the middle row had four; the characters were separated by a single space. The missing position in the second row was in the middle of that row. This position was a fixation point which was created by illuminating the card from behind by a pencil point of a dim red light held flush against the back of the card. This light was created from a flashlight bulb which, with the exception of the pencil point, was covered with electrical tape. The resulting light did not illuminate any of the letters.
\end{abstract}

\section{Subjects}

Five undergraduate students from the State University of New York at Buffalo participated in the experiment as part of their introductory psychology course requirement. The sixth subject (number 3 in Table 1) was one of the experimenters (D.H.K.).

\section{Procedure}

The experiment was run in a room in which effort was made to eliminate extraneous light, although slight leakage did occur from cracks along the ceiling and two tape recorders. Only after $12 \mathrm{~min}$ or more of dark adaptation did any of the leakage become even faintly visible.

The subjects were given several trials with the brightest and dimmest filters until they understood the procedure and reported being able to clearly see the display. When instructed to sit as close as possible to the display as long as they could focus clearly, subjects positioned their heads approximately $12 \mathrm{in.} \mathrm{from} \mathrm{the}$ display. After a period of 12 min of dark adaptation, the experiment began with a trial every $30 \mathrm{sec}$, as announced by a prerecorded signal on the tape recorder. The first 10 trials and the first 3 trials in any given filter were considered practice trials and not recorded. Half the subjects started the experiment with the dimmest displays (N.D. filter of .01) and progressively re- 
ceived filters of higher and higher transmittance. The order of the filters was reversed for the other three subjects. Each subject had 75 trials, 25 of which were practice trials, yielding a total of 300 trials from the six subjects. The subjects operated the strobe light with a handswitch. The strobe was mounted on a platform 1 in. from the subject's right ear. The display subtended a visual angle of approximately $2 \mathrm{deg}$. The 13 practice trials were conducted only after 12 min of dark adaptation. No experimental trials were conducted until after approximately 18 min of dark adaptation. The subjects were instructed to fixate on the red light and, on signal from the tape, to press the handswitch. They were told to name as many items as they could "see." Their responses were taped. They were told to close their eyes immediately after firing the flash and to continue to fixate on the (no longer visible) fixation light as if their eyes were still open. This was done in an attempt to reduce the incidence of eye movements which most subjects needed some practice to suppress. The closing of the eyes would also reduce the very slight masking that might have resulted from the small amount of light in the room.

\section{RESULTS AND DISCUSSION}

The subjects were not instructed to guess and a low rate (.52 per trial) of errors of commission (report of an item out of position or not in the display) indicated that they were not guessing. Consequently, it was relatively easy to match a given response sequence of letters and digits to part of the display. Often the subjects would say that they could not see various parts, for example, "lower left," but could accurately provide the letters or digits from a remaining portion, for example, "T 7 J." Table 1 shows the mean number of correct responses at each filter transmittance for each subject. Errors of commission, in which an item was either not present in the display or not in its correct position, are also shown.

At $80 \%$ transmittance, the subjects with the ascending order averaged 12.4 characters correctly reported. Subject 3 (D.H.K.) was able to report 13.5 letters at this transmittance. Although it is possible that his higher performance could have reflected knowledge of the displays, subsequent tests con- firmed his high capacity for performing this task. This capacity was more likely a reflection of his ability to suppress eye movements during the persisting image. Also, he showed the same effect of transmittance as did the other subjects. In general, as stimulus intensity was increased, the number of items correctly reported increased $[\mathrm{F}(4,25)=11.59, \mathrm{p}<$ $.001]$. The lack of a positive relation between errors of commission and luminance indicates that the high number of correct items at the higher transmission levels was not caused by an increased willingness to guess at these levels. The higher performance with the ascending order of filters at the highest transmittance likely reflects the increased practice that these subjects had for suppressing eye movements. The equivalent performance for ascending and descending groups at the lower transmittance levels could have reflected differences in ability to perform this task (favoring the ascending group) or a reduced need to suppress eye movements for displays when many of the items were unintelligible even with a steady fixation.

With only modest levels of practice, the subjects achieved an extremely high rate of performance with the high-luminance displays. The three subjects who received the filters in ascending order were able to correctly report 12.4 out of the 14 letters with the $80 \%$ transmittance filter. In fact, there were nine trials (seven by D.H.K. and two by Subject 1) with this filter in which all 14 letters were correctly reported. (Subject 4 had one perfect trial with the $10 \%$ filter.) Overall, there were 17 trials ( 4 by D.H.K.) in which 13 letters were correct.

The high correlation between performance and display luminance suggests that the persistence was largely retinal. Under nondark-adapted conditions, variations in luminance have little effect on the accuracy of report (Sperling, 1963). Since the displays were presented on the fovea and fine detail was retained in the ghost, the persistence was, most likely, a function of the cone system.

Table 1

Mean Number of Letters Reported Correctly and Errors of Commission as a Function of Stimulus Intensity

\begin{tabular}{|c|c|c|c|c|c|c|c|c|c|c|c|}
\hline \multirow[b]{3}{*}{ Filter Order } & \multirow[b]{3}{*}{ Subject } & \multicolumn{10}{|c|}{ Percent Transmittance } \\
\hline & & \multicolumn{2}{|c|}{$80 \%$} & \multicolumn{2}{|c|}{$10 \%$} & \multicolumn{2}{|c|}{$.1 \%$} & \multicolumn{2}{|c|}{$.1 \%$} & \multicolumn{2}{|c|}{$.01 \%$} \\
\hline & & Letters & Errors & Letters & Errors & Letters & Errors & Letters & Errors & Letters & Errors \\
\hline Ascending & $\begin{array}{l}1 \\
2 \\
3^{*}\end{array}$ & $\begin{array}{l}12.3 \\
11.5 \\
13.5\end{array}$ & $\begin{array}{l}.40 \\
.60 \\
.00\end{array}$ & $\begin{array}{r}8.2 \\
10.0 \\
11.1\end{array}$ & $\begin{array}{l}.40 \\
.80 \\
.20\end{array}$ & $\begin{array}{l}5.4 \\
7.3 \\
8.8\end{array}$ & $\begin{array}{l}.70 \\
.80 \\
.10\end{array}$ & $\begin{array}{l}4.4 \\
6.4 \\
7.4\end{array}$ & $\begin{array}{r}.50 \\
1.20 \\
.10\end{array}$ & $\begin{array}{l}3.9 \\
5.9 \\
6.2\end{array}$ & $\begin{array}{l}.70 \\
.90 \\
.00\end{array}$ \\
\hline Mean & & 12.4 & .33 & 9.8 & .47 & 7.2 & .53 & 6.1 & .60 & 5.3 & .53 \\
\hline Descending & $\begin{array}{l}4 \\
5 \\
6\end{array}$ & $\begin{array}{l}9.6 \\
7.9 \\
8.3\end{array}$ & $\begin{array}{l}.70 \\
.10 \\
.10\end{array}$ & $\begin{array}{r}12.2 \\
7.6 \\
7.3\end{array}$ & $\begin{array}{l}.40 \\
.40 \\
.50\end{array}$ & $\begin{array}{l}8.9 \\
7.5 \\
4.7\end{array}$ & $\begin{array}{r}1.30 \\
.00 \\
.40\end{array}$ & $\begin{array}{l}5.9 \\
5.5 \\
4.2\end{array}$ & $\begin{array}{r}1.60 \\
.10 \\
.40\end{array}$ & $\begin{array}{l}5.0 \\
5.3 \\
3.8\end{array}$ & $\begin{array}{r}1.00 \\
.90 \\
.30\end{array}$ \\
\hline Mean & & 8.6 & .33 & 9.0 & .37 & 7.0 & .57 & 5.2 & .73 & 4.7 & .73 \\
\hline Overall Mean & & 10.5 & .33 & 9.4 & .42 & 7.1 & .55 & 5.6 & .67 & 5.0 & .63 \\
\hline
\end{tabular}

*D.H.K. 
We will conclude with some observations about the subjective nature of the visual persistence. With the $80 \%$ transmittance filters, the display appeared to remain legible for 3 or $4 \mathrm{sec}$. However, subjects reported being able to see the display for as long as 15 to $30 \mathrm{sec}$ after the flash (with their eyes closed) but without a capacity to read individual letters at these intervals.

In addition to learning to suppress eye movement, it was also necessary to learn which aspects of the visual experience following the flash to attend to. Specifically, "hot spots" would often appear immediately following the flash. Bidwell's ghost was often not apparent immediately after the flash but would make an appearance 1 or $2 \mathrm{sec}$ later. If one attended to the hot spots, then the information in Bidwell's ghost could be missed. Consequently, it was necessary to learn to attend to the ghost and to ignore other aspects of the visual experience. Often the ghost would wax and wane, although its reappearance rarely was sufficiently detailed to provide any additional letters.

Bidwell's ghost can also provide an interesting testing ground for visual capture (Rock \& Harris, 1968). This can be experienced in at least two ways. If one looks at one's own hands during the flash and then places them behind the back, the appearance of the hands in Bidwell's ghost exerts a curious kinesthetic effect in which the hands are (somewhat) felt as being in front of the body. A second phenomenon is the "ventriloquism effect." If one looks at another person during the flash, and that person walks away from the initial position while talking, the voice will often be heard as emanating from the original position.

\section{CONCLUSIONS}

When a display of 14 letters and digits was illuminated by a bright $1-\mathrm{msec}$ flash (not followed by a mask), practiced, dark-adapted subjects were able to report 12.4 of the items. This was their average full report, not an estimate from a partial report. This high level of performance documents the clarity of the long-lasting, positive afterimages originally reported in the last century and termed "the ghost" by S. Bidwell. It is thus possible for a full report of a brief visual display to contain far more than the usual estimate of 3 to 4 letters first reported by Sperling (1960). Several trials were recorded in which subjects were able to report all 14 letters.

\section{REFERENCES}

Averbach, E., \& Coriell, A. S. Short-term memory in vision. Bell System Technical Journal, 1961, 40, 309-328.

DUKE-ELDER, S. W. Text-book of ophthalmology (Vol. 1). The development form and function of the visual apparatus. St. Louis: C. V. Mosby, 1932. (2nd impression, 1938)

Rock, I., \& Harris, C. S. Vision and touch. Scientific American, 1967, 216, 96-104.

Sperling, G. The information available in brief visual presentations. Psychological Monographs, 1960, 74 (Whole No. 498).

Spe rling, G. A model for visual memory tasks. Human Factors, $1963,5,19-31$.

\section{NOTE}

1. This phenomenon was independently discovered by Donald Burke, who brought it to our attention. We acknowledge our indebtedness to Mr. Burke.

(Received for publication March 25, 1980; accepted March 28, 1980.) 